\title{
Heisenberg on Science, Language, and the Question of Objectivity ${ }^{1}$
}

\begin{abstract}
Far from regarding physical science as a universal model of human knowledge, Werner Heisenberg relativized the scientificity of natural science, situating this domain of knowledge in a wide range of our modes of experiencing the world. In this paper, with a focus on his critical analysis of the notion of objectivity in quantum theory and other fields, I survey Heisenberg's view of the world as divided into six distinct areas of reality, including - but not centered on physical science. I also seek to show how this conception of the structure of reality, specifically of the relation between different areas of reality, is mediated by his mis- or reinterpretation of Bohr's idea of complementarity.
\end{abstract}

\section{Keywords}

Heisenberg, quantum theory, Bohr, complementarity, science, philosophy, objectivity, reality, language

\begin{abstract}
Weit davon entfernt, die Physik als Universalmodell für menschliche Erkenntnis anzusehen, relativierte Werner Heisenberg die Wissenschaftlichkeit der Naturwissenschaft, indem er diesen Wissensbereich in ein breites Spektrum unserer Welterfahrungsmöglichkeiten einordnete. Dieser Aufsatz präsentiert - mit Blick auf Heisenbergs kritische Analyse des Begriffs der Objektivität im Bereich der Quantentheorie und auf anderen Gebieten - die Weltsicht Heisenbergs und deren Einteilung in sechs unterschiedliche Wirklichkeitsbereiche, unter denen auch die Physik vertreten ist, ohne dabei das Zentrum zu bilden. Ich versuche darüber hinaus zu zeigen, wie seine Vorstellung von der Struktur der Wirklichkeit, insbesondere von der Beziehung zwischen verschiedenen Wirklichkeitsbereichen, durch eine Fehl- bzw. Uminterpretation von Bohrs Komplementaritätsgedanken geprägt ist.
\end{abstract}

\section{Schlüsselwörter}

Heisenberg, Quantentheorie, Bohr, Komplementarität, Wissenschaft, Philosophie, Objektivität, Wirklichkeit, Sprache

Science, especially modern natural science, is commonly recognized as a system of objective knowledge or as an activity that is considerably successful in attaining the goal of objectivity. Even parts of social science and the humanities are seeking increasingly to follow the model of natural science to establish themselves as objective sciences. In this sense, objectivity constitutes an essential component of what is considered the scientificity of science.

* The author teaches philosophy at Akita University, Japan. He holds a Ph.D. in Philosophy from the Vrije Universiteit, the Netherlands. His recent publications include Gendai-nihon-tetsugaku o tou: "wareware" to sono kanata [Questioning Contemporary Japanese Philosophy: The We and Beyond] (2009). E-mail: katsumor@gipc.akita-u.ac.jp

1 This article is based on a paper with the same title presented by the author at the symposium "Reflecting on the Scientificity of Linguistics," held at Akita University, Japan, in March 2010. 
It is worth recalling, however, that, in the history of modern science, particularly in connection with the development of quantum theory in the early twentieth century, the objectivity of knowledge was a critical issue examined by physicists themselves, including some of the very founders of quantum physics. In this paper, I take up the work of the German physicist Werner Heisenberg (1901-1976), who not only co-founded quantum mechanics, but also explored philosophically how objectivity is put in question and restricted in this new theory of physics as well as in other fields of knowledge. In the first section, I outline the main points of his interpretation of quantum theory, and, in the second, survey his general philosophical views with a focus on his critical analysis of the issue of objectivity.

\section{Heisenberg's Interpretation of Quantum Theory}

Quantum theory, a basic theory of modern physics that deals with atomic and subatomic objects and processes, was developed during the first quarter of the twentieth century. In the middle of the 1920s, it was brought to completion as quantum mechanics - in the forms of matrix and wave mechanics - by Heisenberg and other physicists. This new field of physics raised, however, difficult interpretive questions, with which Heisenberg himself, among others, became engaged from then onward.

In 1927, Heisenberg derived from matrix mechanics a set of relations designated by the term "uncertainty" or "indeterminacy," which would prove to be of great significance for the interpretation of quantum theory. He elucidates the meaning of the uncertainty relations with the aid of a thought experiment in which one observes an electron by illuminating it with light or gamma rays. In his account, the change in the momentum of the electron "is the greater the smaller the wavelength of the light employed - that is, the more exact the determination of the position." Since this change itself cannot be determined, "the more precisely the position is determined, the less precisely the momentum is known, and conversely.” This relation may be quantitatively expressed as $\Delta x \cdot \Delta p \sim h$, where $\Delta x$ and $\Delta p$ are the uncertainties of position $x$ and momentum $p$, respectively, and $h$ Planck's constant (WHGW, AI:481). Heisenberg also shows that a parallel relation holds for time $t$ and energy $E: \Delta t \cdot \Delta E \sim h$ (WHGW, AI:485).

In his interpretive approach to quantum theory, Heisenberg stood in a close relationship with his mentor and associate Niels Bohr, who later in the same year presented the idea of "complementarity." Bohr's complementarity may be briefly outlined as follows: Any observation of atomic phenomena involves an unavoidable and uncontrollable interaction with the "agency of observation" or measuring instrument. Therefore, when any observation is carried out, "an unambiguous definition of the state of the system is naturally no longer possible, and there can be no question of causality." On the other hand, the definition of the state of the system "claims the elimination of all external disturbances," in which case "any observation will be impossible, and, above all, the concepts of space and time lose their immediate sense." Faced with this apparent dilemma, Bohr proposes that we "regard the space-time co-ordination and the claim of causality [...] as complementary but exclusive features of the description" (PWNB, 1:54f.). The concept of complementarity, thus introduced, comes to mean not only 'joint completion,' but at the same time "the relation of mutual exclusion [...] with regard to the application of the various classical concepts and ideas" (PWNB, 1:19). Bohr's complementarity thus refers to the relation between space-time coordination and the claim of causality or, equivalently, between the use of space-time concepts and of the dynamical conservation laws, that is, the laws of conservation of energy 
and momentum. It therefore has its quantitative expression in Heisenberg's uncertainty relations.

Bohr's complementarity had such a great impact on Heisenberg that the latter incorporated it in his own interpretation of quantum theory. As some commentators point out, ${ }^{2}$ however, his understanding of complementarity deviates at a crucial point from Bohr's. While following Bohr in speaking of the complementarity of space-time and causality, Heisenberg conceives causality not primarily as the use of the dynamical conservation laws, but rather as a description in terms of the "mathematical schema of quantum theory," that is, the state function or "probability function" (PPQ, 48/64; PP, 49f.). Whether it is a simple misinterpretation or rather a productive reconceptualization, he thereby converts Bohr's complementarity into the relation between a space-time description and a description in terms of the probability function (see Table 1).

Table 1

\begin{tabular}{|c|c|c|}
\hline & Space-time & Causality \\
\hline $\begin{array}{c}\text { Bohr's } \\
\text { complementarity }\end{array}$ & Use of space-time concepts & $\begin{array}{c}\text { Use of the dynamical } \\
\text { conservation laws }\end{array}$ \\
\cline { 3 - 3 } $\begin{array}{c}\text { Heisenberg's } \\
\text { complementarity }\end{array}$ & Space-time description & $\begin{array}{c}\text { Description in terms of } \\
\text { the probability function }\end{array}$ \\
\hline
\end{tabular}

In my view, this suggests that Heisenberg opens up a way of conceiving complementarity as a relation between different areas of reality corresponding to different (here classical and quantum) modes of description. We will see below how this renewed idea of complementarity plays an important role in his general philosophical views.

\section{Heisenberg's Philosophical World View}

Let us now extend our scope to see how Heisenberg develops his philosophical ideas in close connection with, but well beyond, the field of quantum physics.

\section{1. Philosophy of science}

Heisenberg's interpretation of quantum theory as just sketched implies that the objectivity of knowledge is limited in this new physical theory. As he notes, classical physics started from the belief that we could in principle describe the world objectively, that is, "without any reference to ourselves." With the development of quantum theory, however, this belief has proved to be an "illusion" (PP, 55). Heisenberg argues that, in quantum theory, "observation generally changes the state of the system," and by this change he means not only the physical disturbance of the system, but also the change in "our knowledge of the system" (WHGW, CI:251). Since this change itself cannot be objectively determined, it follows that "[q]uantum theory does not allow a completely objective description of nature” (PP, 107).

2 Shingo Fujita, Sōhosei no tetsugakuteki-kōsatsu [Philosophical Investigations on Complementarity] (Tokyo: Taga-shuppan, 1991), pp. 106f.; Kristian Camilleri, Heisenberg and the Interpretation of Quantum Mechanics: The Physicist as Philosopher (Cambridge: Cambridge University Press, 2009), pp. 113ff. 
As we will see below, Heisenberg holds that, in other fields of natural science, specifically biology, the objectivity of knowledge is even more restricted than in quantum theory. This being the case, he makes the following remark on natural science in general: "Natural science does not simply describe and explain nature; it is a part of the interplay between nature and ourselves” (PP, 81). In other words, science "cannot simply speak of nature 'in itself,"” but rather itself constitutes a part of the human's relation to nature (CI:405). ${ }^{3}$

\section{2. Language and reality}

Heisenberg further amplifies his critical analysis of objectivity in a general philosophical account of reality. He claims:

[...] the reality of which we can speak is never reality 'in itself,' but is a known reality or in many cases even a reality to which we ourselves have given form (gestaltet) (CI:236).

It is worth noting that the German word translated here as 'reality' is 'Wirklichkeit' and not 'Realität.' Heisenberg regularly uses the term 'Wirklichkeit,' which, unlike 'Realität,' does not connote thing-like objects existing independently of the knowing subject. To be sure, in his account, a certain fragment of reality "can be objectified with success" (CI:285). He cautions, however, against mistaking "the objectifiable layer of reality" to be "reality as such" and neglecting the greater part of the world that cannot be objectified or fully objectified (CI:298).

In Heisenberg's view, we give form to reality primarily through the medium of language. As he emphasizes, "[a]ny kind of understanding, scientific or not, depends on our language" (PP, 144). It is not that we first have ideas and then express them by means of language, but that our thought is from the beginning bound up with language. The role of language is thus central to Heisenberg's account of reality. As he notes, "every formulation in language not only grasps, but also forms (gestaltet) and idealizes reality" (CI:289). Some might object that "there is finally an objective world" fully independent of our thought and language. To this Heisenberg responds by saying that "for us 'there is' only the world in which the expression 'there is' has a meaning”' (CI:236).

While we thus form reality through language, this activity of formation itself cannot be objectively determined. In Heisenberg's view, this implies an "unavoidable element of indeterminacy (Unbestimmtheit)" in our language. For this reason, no word, in particular, has a fully well-defined meaning. This is not to say that our language fails to express what is clearly determined in our mind. Rather, we are faced with "what is peculiarly 'floating"” in both language and thought (CI:222). Our thinking, bound up with language, thus "always hangs (schwebt) over a bottomless depth” (CI:226).

\section{3. The layered structure of reality}

From 1941 to 42, in the midst of World War II, Heisenberg privately wrote an extensive philosophical manuscript, which would be published only posthumously in 1984 under the title “Ordnung der Wirklichkeit [Order of Reality].” In this manuscript, arguably the most elaborate presentation of his philosophical views, Heisenberg seeks to replace the Cartesian separation of subject and object with a model of different layers of reality that "move up from the objective to the subjective pole" (CI:231). By the objective he means that "the state of

3 Here and in all citations below with the volume number 'CI,' I omit the abbreviated title of the series WHGW (Werner Heisenberg Gesammelte Werke). 
affairs in question can be detached from us and from its description," whereas the subjective signifies the possibility that "we ourselves are interwoven with the connections" (CI:229, 235).

Heisenberg finds in his favorite literary author Goethe's work an idea of ordering reality that comes close to his own. Goethe groups all "effects" we experience in the world into the following nine kinds: “accidental, mechanical, physical, chemical, organic, psychic, ethical, religious, [and] genial” (CI:232). Drawing on but partly modifying Goethe's scheme, Heisenberg divides the world into the following six areas (Bereiche): classical physics, chemistry, organic life, consciousness, symbol and form, and creative powers (see Table 2).

Table $2^{4}$

\begin{tabular}{|c|c|}
\hline Goethe & Heisenberg \\
\hline & [Objective pole] \\
\hline Accidental & \\
\hline Mechanical & (Classical) physics \\
\hline Physical & Chemistry \\
\hline Chemical & Organic life \\
\hline Organic & Consciousness \\
\hline Psychic & Symbol and form \\
\hline Ethical & Creative powers \\
\hline Religious & [Subjective pole] \\
\hline Genial & \\
\hline
\end{tabular}

As Heisenberg stresses, the transition between different areas of reality is not continuous. Rather, there is an "abyss" between the areas that "cannot be bridged by logical inference or consistent development of language" (CI:226). Nevertheless, the different areas are not simply disconnected, but in a certain way "match" each other (CI:236). As the reading of the text will show, to characterize the relations between the different areas, Heisenberg extensively employs the idea of complementarity - not exactly Bohr's complementarity, but complementarity as reinterpreted by Heisenberg himself.

Heisenberg starts with "classical physics" as the most objective area of reality. In his account, classical physics, which comprises the theories of Newtonian mechanics and electrodynamics, represents "the idealization of reality in which one speaks only of objective material processes in space and time - independently of the question of how these processes can be found out” (CI:255f.).

This is no longer the case with the next, second area of reality, which is "chemistry" or rather its theoretical basis: quantum theory. In Heisenberg's view, because of the observational

4 This is based on a table presented by Gregor Schiemann in his book Werner Heisenberg (Nördlingen: Verlag C. H. Beck. 2008), p. 95. For my overview of Heisenberg's “Ordnung der Wirklichkeit," I am indebted to Schiemann's work just mentioned as well as Catherine Chevalley's "Introduction” to the French translation of Heisenberg's text: Philosophie: le Manuscrit de 1942, French trans. Catherine Chevalley (Paris: Éditions du Seuile, 1998). 
intervention in the atomic system, "not all properties of the system can at the same time be objectified," but the objectification of a certain property - specifically of the probability function - "excludes the knowledge of certain other properties" (CI:251). This implies a complementary relation between the mechanical and the chemical modes of description:

[. . .] the state of an atom in which we know its chemical behavior cannot be described in terms of mechanical movements of the building blocks of the atom, while conversely a more exact knowledge of the mechanical behavior of the electrons makes impossible the knowledge of the chemical properties (CI:252).

Here we can see how Heisenberg starts using the idea of complementarity as a relation between different areas of reality.

The third area of reality for Heisenberg is “organic life.” In his account, although the laws of quantum theory play an important role in the biological phenomena, this in no way means that biology may be reduced to physics. Rather, following Bohr, he argues that "the careful description of living processes" is complementary to their physical and chemical analysis (CI:259). The statement, for example, that something is a living cell "stands in an exclusive relation to the exact knowledge of its quantum-theoretical state," because any attempt to obtain such exact knowledge will lead to a destruction of the life of the cell (CI:265).

The area next to biological life is "consciousness," which, in Heisenberg's view, cannot be reduced to material processes. Specifically, we cannot locate the soul "in space and time in a completely definite way” (CI:283). In more general terms, “an essential part of psychological (seelisch) events evades, up to a certain degree, objective specification, because the act of specification (Fixierung) itself decisively interferes in the processes” (CI:275).

The next area of reality is designated as "symbol and form (Gestalt)." Heisenberg gives the example of the "rose," which serves as a symbol of "life and youth," and is thus "for us humans more than all [...] that could be established in biological or physico-chemical concepts" (CI:279). Certain symbols can be specialized in such a way as to condition all our understanding and thinking, and the most typical set of such symbols is "language and writing” (CI:280). Here again Heisenberg points to a complementary relation: Access to the environment through language and rational thinking is complementary to "the biological linkage (Verknüpfung) to this environment." Migratory birds, for example, "find the way to the south precisely because they cannot think or speak of the way they arrive there" (CI:281).

Heisenberg finally arrives at the highest layer of reality, namely "creative powers," of which he gives the examples of love, religion, and artistic inspiration. This part of reality can by no means be objectified, and can be spoken of "only in parables" (CI:294). Although this area is characterized as subjective, this does not mean that we can freely create or change it as we wish to. Creative powers are not driven by human will, but belong to "the sea of unconscious psychological processes" (CI:295). In this area, humans are no longer simply humans, but rather the sites where creative powers work even "beyond everything human." This means, Heisenberg suggests, that what emerges here is "both the most objective and the most subjective” (CI:300).

As we have seen so far, Heisenberg by no means takes for granted physical science as a universal model of human knowledge. On the contrary, through a critical analysis of the question of objectivity, he relativizes the scientificity of natural science, situating this domain of knowledge in a wide range of our different modes of experiencing the world. I have also 
suggested how Heisenberg's mis- or reinterpretation of complementarity plays a crucial, productive role in his conception of the layered structure of reality.

There seem to remain, however, some unsolved problems in Heisenberg's philosophical world view. While attending closely to the structural complexity of reality, he nevertheless characterizes this structure as a linear series of areas ranging between the two poles, objective and subjective. To this extent, notwithstanding his criticism of the subject/object separation, his overall theoretical framework appears to remain within the modern subject-object schema. In his actual description, however, Heisenberg focuses on language, in particular, which belongs to the specific area of 'symbol and form' and yet is constitutive of our whole relation to reality. He also enters into such issues as the unconscious, which seems to be difficult to situate in the linear axis of subject-object. In my view, these elements tend to go beyond his manifest framework of the order of reality. This suggests that Heisenberg's philosophical thought should be subject to further examination and perhaps be modified or transformed into a new conception.

\section{Abbreviations}

Works by Niels Bohr:

PWNB - The Philosophical Writings of Niels Bohr, 4 vols. (Woodbridge, Conn.: Ox Bow Press, 1987-98)

Works by Werner Heisenberg:

PP _ - Physics and Philosophy: The Revolution in Modern Science (New York: Harper \& Row, Publishers, 1958)

PPQ - Physikalische Prinzipien der Quantentheorie (Stuttgart: S. Hirzel Verlag, 1958); Eng. trans. Carl Eckart and F. C. Hoyt, The Physical Principles of the Quantum Theory (New York: Dover Publications, 1949)

WHGW - Werner Heisenberg Gesammelte Werke/ Collected Works, AI-III, B, and CI-V (Berlin: Springer Verlag; München: Piper Verlag, 1984-89) 